\title{
Inovando Métodos de Ensino-Aprendizagem na Formação do Psicólogo
}

\section{Vera Lucia \\ Kodjaoglanian}

Psicóloga, mestre em saúde coletiva

coordenadora do curso

de Psicologia da

UNIDERP.

\section{Clarice Cristina} Andrade Benites

Psicóloga, Mestranda em Psicologia, docente do curso de Psicología da UNIDERP, responsável pelas habilidades de

técnicas de exames psicológicos no curso e pelo sistema de avaliação.

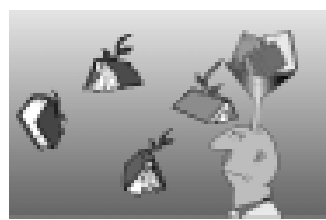

Irma Macário

Psicóloga, Mestranda em Meio Ambiente e

Desenvolvimento

Regional, coordenadora da clínica integrada de psicologia da UNIDERP.

\section{Maria Celia Esgaib \\ Kayatt Lacoski}

Psicóloga, mestre em saúde coletiva, docen-te do curso de Psico-logia da UNIDERP, res-ponsável

pelo labo-ratório de

Psicologia Experimental do curso.

Resumo:Este artigo destaca a importância da implantação de novos métodos de ensino-aprendizagem no ensino de Psicologia, habitualmente fundamentado no domínio e na transmissão de conhecimentos e habilidades e na memorização de informações, que geralmente não conduzem a uma prática profissional adequada. A proposta aqui apresentada destaca o papel ativo do aluno no processo ensino-aprendizagem, que se dá com base em problemas que possibilitam ao aluno estudar conteúdos segundo necessidades concretas e explicita a concepção teórico-metodológica e operacional de um curso que tem como ferramenta pedagógica o PBL (Problem Based Learning).

Palavras-Chave: Ensino em Psicologia, métodos de ensino, aprendizagem baseada em problemas.

Abstract:The present article emphasizes the importance of implanting new teaching/learning methods in Psychology courses, traditionally based on the presumption that mastering the transmission of knowledge and the memorization of information and abilities that generally do not lead to an adequate professional practice. The proposal presented here emphasizes the active role of the student in the learning process, carried out on the basis of problems, which permits the student to study informational content according to his concrete necessities and explains the theoretical, methodological and operational concept of a course based on the teaching tool PBL - (Problem Based Learning).

Key Words: Psychology courses, teaching methods, problem based learning.

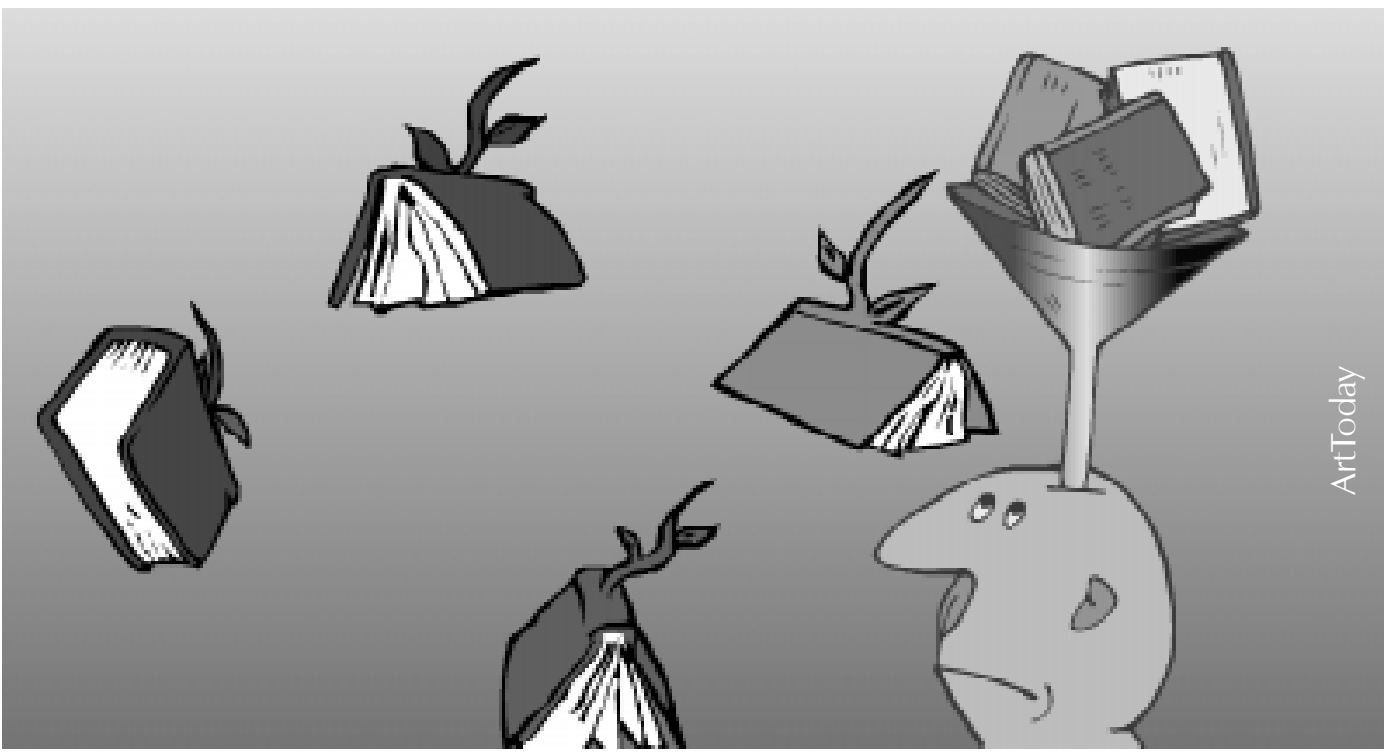

Em função da progressiva capacidade do setor saúde em atender, de forma minimamente aceitável, as necessidades de uma sociedade em transformação, intensificam-se, nas últimas duas décadas, importantes tentativas de mudança do modelo hegemônico flexneriano de formação de profissionais nesse campo.

Nesse sentido, destacam-se movimentos na América Latina como o dos "Projetos IDA" (Integração Docente Assistencial), "Saúde para Todos" e sua estratégia principal, a Atenção Primária à Saúde (UNICEF, 1978) e o Programa UNI, apoiado pela Fundação Kellogg (Kisil e Chaves, 1994).

O Estudo Baseado em Problemas -PBL (Problem Based Learning) é um método de ensino, aplicado pioneiramente nas ciências médicas, cujos fundamentos e pressupostos epistemológicos remontam à história das investigações da Psicologia no âmbito do desenvolvimento maturacional do ser humano e dos processos de aprendizagem. Tais 
fundamentos embasam as teorias construtivistas da aprendizagem. Estas, muitas vezes confundidas com métodos de ensino, na verdade buscam discutir epistemologicamente os processos de aprendizagem e a postura do educador frente ao aluno que constrói seu conhecimento. A partir das experiências realizadas há cerca de trinta anos em diversas instituições de ensino superior, o PBL tem-se mostrado eficiente em desenvolver no estudante a responsabilidade e atitude em seu aprendizado e a construção do conhecimento e de habilidades.

Inspirada nessas experiências e motivada pela necessidade de se buscar alternativas metodológicas para um ensino voltado à realidade contem-porânea, a Universidade para o Desenvolvimento do Estado e da Região do Pantanal-MS (UNIDERP) implantou, no final do ano de 1999, o curso de Psicologia.

O objetivo dessa nova proposta pedagógica é formar psicólogos dentro de uma visão de qualidade profissional a partir de um modelo educacional inovador, baseado em valores e práticas humanísticas e capaz de intervir de forma efetiva, crítica e criativa no contexto social em que o curso está inserido.

\section{O Modelo Pedagógico do Curso}

No trabalho pedagógico, a metodologia de ensino ocupa um papel central na formação e no desempenho do educador, pois, além de fornecer subsídios técnicos para o desenvolvimento de seu trabalho, constitui referencial importante, dentro de uma visão histórico-crítica da sociedade, para a formação do cidadão.

Entendendo a metodologia de ensino como processo de construção do conhecimento a partir da relação professor-aluno/transmissão-assimilação, inserido em uma reflexão social e política, podemos dizer que, da forma como o educador compreende e vivencia sua prática, depende o resultado que irá alcançar com seus alunos (Mizukami, 1986).

Para Saviani(1991, p82) "a compreensão da prática social passa por uma alteração qualitativa [...]", sendo a prática social o ponto de partida e o ponto de chegada do processo metodológico de ensino. Constitui-se, ao mesmo tempo, suporte e contexto, fundamento e finalidade. E, pela mediação da ação pedagógica, transforma os agentes de aprendizagem em agentes sociais.

Além dos conceitos subjacentes à prática metodológica, esta configura-se como estratégia de ensino-aprendizagem. Como tal, é ela quem possibilita a organização pedagógica da prática do educador, oferecendo-lhe o instrumental necessário ao desenvolvimento do pensar e a construção de conhecimentos por parte do aluno (ROSS, 1998). Dentro da visão apresentada, implica também formação de cidadãos conscientes de sua história.

Nesse contexto, o papel que o conhecimento cotidiano deveria desempenhar no conhecimento escolar e a diferença entre aquele e o conhecimento científico torna-se uma questão ainda mais importante quando se trata da educação em ciências médicas e sociais (odrigo e Arnay, 1998).

Parte-se da constatação de que, depois de tantos anos, não se conseguiu fazer com que o conhecimento acadêmico se constitua instrumento de análise, reflexão e ação a serviço daqueles que passam quase um quarto de século de sua vida aprendendo institucionalmente. Por isso, é possível que muitas pessoas não considerem interessante, após a conclusão de sua formação acadêmica, continuar ampliando seu conhecimento, apesar de contarem com instrumentos adequados para fazê-lo.

Em linhas gerais, o valor e o sentido do que se ensina nas escolas, institutos e universidades estão tão afastados do cotidiano quanto do científico. Do cotidiano, porque não se prevê que sua obtenção sirva para a reflexão e ação, já que as pessoas elaboram modelos implícitos que servem para interpretar os fenômenos ocorridos nas dimensões intermediárias da realidade; enquanto o conhecimento acadêmico tenta transmitir, principalmente, os modelos e teorias científicas sobre dimensões do micro e do macro mundo.

Um debate que parece ter certa relevância nas atuais perspectivas sobre a construção do conhecimento questiona se os processos de ensino devem propiciar um modelo de construção dependente de princípios e mecanismos cognitivos de caráter geral, independentemente dos conteúdos e dos contextos sobre os quais opera, ou se, pelo contrário, devem-se potencializar as estratégias e procedimentos para que eles sejam contemplados de maneira específica, isto é, em estreita relação com o tipo de tarefas e demandas apresentadas em contextos determinados (Bordenave, 1977).

Embora paradoxal, parece que o papel do conhecimento científico na escola ainda não foi definido, ou que não existe um conhecimento escolar específico. Isto significa que se deveria esclarecer, entre outros aspectos, a opção, ou não, por se adotar: transmitir informação científica, formar futuros cientistas, criar consumidores de ciência, pessoas críticas diante do desenvolvimento científico e tecnológico.

Dependendo da opção, os caminhos a serem seguidos no ensino e na aprendizagem da ciência podem variar substancialmente. Por exemplo, quando se volta o olhar para os problemas detectados no ensino das disciplinas científicas, podemos verificar que muitas

\section{Sonia Maria Oliveira de Andrade}

Psicóloga, doutoranda em saúde coletiva.

\section{Vera Nice \\ Assumpção \\ Nascimento}

Psicóloga, mestre em saúde coletiva, docente do curso de Psicologia da UNIDERP, responsável pelas habilidades de Dinâmica de Grupo no curso e habilidade de Teorias e Técnicas Psicoterápicas

\section{José Lúcio Machado}

Médico, especialista em metodologias pedagógicas inovadoras, consultor pedagógico do método PBL na UNIDERP. 
Vera Lucia Kodjaoglanian, Clarice Cristina Andrade Benites, Irma Macário, Maria Celia Esgaib Kayatt Lacoski, Sonia Maria Oliveira de Andrade, Vera Nice Assumpção Nascimento, José Lúcio Machado

delas são motivadas pelas dificuldades encontradas na hora de os alunos adotarem um referencial interpretativo científico na análise da realidade.

Na verdade, cada disciplina que forma o currículo escolar tem suas próprias restrições para se ligar à realidade cotidiana. A partir de determinados limites, relacionar o conhecimento cotidiano e o científicoé uma tarefa quase impossível. Tudo isso leva a aceitar, em último termo, que as disciplinas acadêmicas se justificariam dentro do sistema educativo, mas nem sempre servem para ser usadas como suporte que as qualifiquem para uma compreensão mais científica da realidade cotidiana.

A aprendizagem baseada em problemas - PBL (do inglês Problem Basead Learning) - é um método de ensino considerado inovador, que vem sendo desenvolvido há cerca de trinta anos em algumas universidades da Europa, EUA (Venturelli, 2000; University OF Maastricht, 2000) e, mais recentemente, na América Latina, na Universidade de Colima, México (Universidade de Colima, 1999).

Oensino dos profissionais de saúde, habitualmente, tem se fundamentado na presunção de que o domínio e a transmissão de conhecimentos e habilidades, lastreados nos últimos avanços técnico-científicos, conduzem necessariamente a uma prática profissional adequada.

\section{Devemos ensinar o aluno a aprender, permitindo que ele busque o conhecimento nos inúmeros meios de difusão do conhecimento hoje disponiveis e que aprenda utilizar $e$ pesquisar nesses meios, como objetivo de facilitar o acesso à diversidade de informações, em contraposição à unicidade do conhecimento do professor. \\ Contudo, em geral, as práticas a partir das quais são realizados os treinamentos constituem simulação do trabalho profissional, pois, apesar de envolver personagens reais, desenvolvem-se em condições e cenários muito distintos daqueles encontrados nas situações de trabalho concretas. Essa dicotomia entre a formação e a prática profissional tem sido uma das forças propulsoras da busca de modelos alternativos de formação de recursos humanos para a saúde. Os novos modelos buscam substituir processos de memorização e transferência unidirecional fragmentadas pelo autoaprendizado e pela educação permanente (Almeida, Feuerwerker e Llanos, 1999). \\ O PBL consiste na integração das disciplinas clássicas em módulos de ensino, com temática específica, trabalhada a partir da discussão de problemas e busca de informações e subsídios teóricos e técnicos para a sua solução. O aluno, segundo Komatsu (1988a), é incentivado a ser responsável pela sua aprendizagem à medida que seus estudos são fundamentados na pesquisa.}

De acordo com Davini (s.d), currículo integrado é um plano pedagógico e sua correspondente organização institucional que articula dinamicamente trabalho/ ensino, prática/teoria e ensino/comunidade. As relações entre trabalho e ensino, entre os problemas e suas hipóteses de solução devem ter sempre, como pano de fundo, as características socioculturais do meio em que esse processo se desenvolve.
Na concepção contemporânea, o modelo de ensino tem tendências que estão moldadas às necessidades de adaptação, tanto da instituição como do corpo docente e discente, e às mudanças da ciência e da sociedade, que ocorrem em velocidade exponencial. O PBL tenta corresponder a essas necessidades e aos paradigmas da aprendizagem fundamentados na epistemologia construtivista (Monroe, 1972).

Quatro grandes eixos compõem o método PBL, de acordo com Venturelli (2000): o currículo integrado, com a fusão das disciplinas científicas em eixos temáticos; o estudo baseado em problemas fundamentados na realidade implicando pesquisa e discussão em pequenos grupos para sua resolução, compreensão e aquisição do conhecimento, a inserção dos acadêmicos em serviços públicos de saúde e educação, levando a um grau de importância significativa o conhecimento e o contato com o cotidiano para a aprendizagem e, por fim, a avaliação em metodologia diferenciada, propiciando contemplar sua verdadeira função, qual seja, o amadurecimento da situação avaliada.

As escolas médicas pioneiras na adoção do método são as de McMaster, no Canadá e de Maastricht, na Holanda. Na última década, o método tem-se difundido em outras escolas médicas e de Psicologia. Nos EUA, as escolas de Albuquerque, de Harvard e do Hawaí, entre outras, adotaram-no. O método tem sido recomendado pelas sociedades de escolas médicas e inúmeras escolas da África, da Ásia e da América Latina, sob supenvisão de uma das duas pioneiras, têmno aplicado. Outras escolas da área da saúde, como Enfermagem, Fisioterapia, Veterinária e Odontologia têm adotado o método com sucesso e, recentemente, escolas das áreas de humanas, tais como a Faculdade de Economia da Universidade de Maastrichte algumas escolas de engenharia dos EUA, por exemplo, demonstrando que o método não é particularmente próprio do ensino da medicina, mas é aplicável ao ensino de qualquer ramo do conhecimento.

O currículo médico tradicional, de acordo com Almeida (1999), baseado na divisão de disciplinas e ciclos básico, clínico e profissionalizante, que a maioria das escolas médicas adota, surgiu na década de 20, nos EUA, proposto pela comissão Flexner-comissão de avaliação dos cursos de Medicina dos EUA. Essa comissão fora encarregada de verificar quais escolas médicas atuantes naquele país no início do século poderiam continuar seus trabalhos. Como resultado, a comissão propôs que o currículo médico deveria constar de alguns anos de aprendizado de ciências ditas básicas da Medicina, tais como a Anatomia, a Fisiologia, a Histologia, a Anatomia Patológica e a Bioquímica, alguns anos de formação clínica e que as escolas deveriam dispor de um hospital para estágio 
dos alunos. Naquela época, não havia residência obrigatória, tal como conhecemos hoje. Sobretudo no pós-guerra, modificações extremamente importantes ocorreram na Medicina, com poucas alterações na estrutura do currículo. Uma das poucas alterações do modelo de ensino médico foi a incorporação da residência médica, primeiro de um ano, e, nas últimas duas décadas, geralmente de dois anos. As disciplinas pré-residência ficaram comprimidas nos primeiros quatro anos do curso e ampliaram seus conteúdos. Com a emergência das especialidades, as disciplinas clínicas multiplicaram-se, sendo estas responsáveis por um significativo aumento das informações, em detrimento, cada vez maior, do exercício prático da Medicina.

A partir da década de setenta, tem surgido melhoria do conhecimento da Psicologia do aprendizado do adulto, mostrando a importância da sua participação ativa na incorporação do conhecimento, a importância de sua experiência prévia e do uso dessa experiência como elemento motivador para o aprendizado. Parte desses conhecimentos foram desenvolvidos a partir dos estudos de Paulo Freire (2000), de parte das teorias de Piaget (1983) e ainda de outra parte nos estudos de profissionais que têm trabalhado nas escolas médicas citadas. A Fisiologia da Memória e seu desenvolvimento recente favoreceu a compreensão da importância da experiência prévia na aquisição de novos conhecimentos.

Um dos fundamentos principais do método PBL, segundo Komatsu (1998b), é que devemos ensinar o aluno a aprender, permitindo que ele busque o conhecimento nos inúmeros meios de difusão do conhecimento hoje disponíveis e que aprenda a utilizar e a pesquisar nesses meios, com o objetivo de facilitar o acesso à diversidade de informações, em contraposição à unicidade do conhecimento do professor. Essa postura faz sentido no mundo atual, pois raramente os assuntos aprendidos nos primeiros anos permanecerão intocados até quando o aluno estiver se formando. Só a postura de estudo e aprimoramento permanente torna possível a sobrevivência profissional em um mundo de economia e conhecimentos globalizados, com um ritmo de circulação de informações e de mudanças. A agilidade é outro elemento que o aluno precisa aprender na graduação, assim como a criatividade de explorar novos métodos de organização profissional.

O PBL, então, não só requer, como também ajuda a desenvolver posturas e habilidades profissionais e pessoais no aluno, na medida em que está estruturado para atender pelo menos os conteúdos referidos acima.

A avaliação dos alunos formados em escolas que adotam o método tem demonstrado que eles desenvolvem a independência, retêm por mais tempo os conhecimentos adquiridos e elaboram uma postura inquisitiva de estudo permanente.

No ano de 1999, a Universidade para o Desenvolvimento do Estado e da Região do Pantanal, UNIDERP (1999), instituição do ensino superior de Campo Grande-MS, buscou a implantação dos cursos de Medicina e Psicologia. Desde já, era sabido que o curso de Medicina funcionaria em uma metodologia diferenciada, que estava tendo bons resultados em outras universidades do Brasil e contava anos de experiência na Europa e EUA.

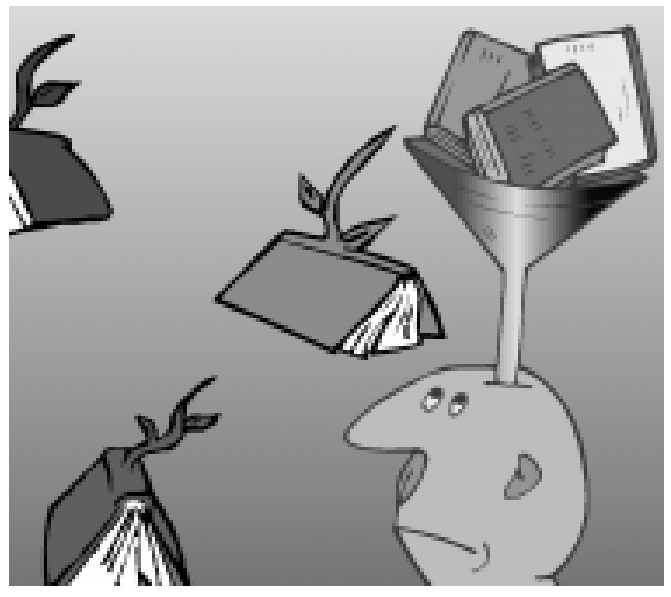

O Aprendizado Baseado em Problemas destaca o uso de um contexto clínico-social para o aprendizado, promove o desenvolvimento de habilidades de trabalhar em grupo e também estimula o estudo individual, de acordo com os interesses e o ritmo de cada estudante.
O grupo de psicólogos convidado para gerenciar a implantação do curso de Psicologia foi chamado a participar da capacitação de docentes para atuar com esse método. Naquela oportunidade, o que ouviram os fez repensar o curso de Psicologia, tendo em conta a visível adequação do método às diretrizes recomendadas pelo $M E C$, e, especialmente às características próprias da ciência psicológica.

Porém, diferentemente do curso de Medicina, não havia nenhuma experiência no Brasil que pudesse servir de referência, o que implicou criar e desenvolver um currículo em PBL para o curso de Psicologia: um desafio. Sem modelos prévios, tornou-se um extraordinário exercício de criatividade, inspirado na experiência acumulada na organização de cursos de Medicina e de Psicologia em Colima e Maastricht. Para tanto, contou-se com equipe de consultores vinculados à Faculdade de Medicina da UNESP de Botucatu e ao projeto UNI - União com a Comunidade, financiado pela Kellog's Fundation, que teve por finalidade impulsionar as mudanças do ensino médico no Brasil.

O suporte dessa consultoria trouxe segurança para que se pudesse ousar e inovar de uma forma tão pioneira, estruturando-se o primeiro curso de Psicologia, centrado na metodologia PBL, em território brasileiro. 
Vera Lucia Kodjaoglanian, Clarice Cristina Andrade Benites, Irma Macário, Maria Celia Esgaib Kayatt Lacoski, Sonia Maria Oliveira de Andrade, Vera Nice Assumpção Nascimento, José Lúcio Machado

O êxito dessa primeira fase comprovou-se com a implantação efetiva do curso dentro dessa metodologia, inaugurando-se a primeira turma em fevereiro de 2000.

\section{O projeto pedagógico procurou:}

integrar as dimensões psicológica, social, biológica, ecológica e político-econômica em todos os momentos do curso de graduação. Para tanto ele é organizado por meio de módulos;

orientar-se em sua construção por processos básicos do campo de construção da subjetividade, fenômenos psicológicos, ciclo de vida, integrando um conjunto nuclear de conhecimentos, habilidades e atitudes que são desenvolvidos como objetivos educacionais (Kodjaoglanian, 2000, p.17).

No curso de Psicologia cada semestre acadêmico é composto de cinco módulos de ensino, sendo dois destinados à aprendizagem teórica realizada a partir das sessões tutoriais e do estudo autodirigido, um das habilidades específicas da Psicologia, um das habilidades gerais do profissional de saúde, e, por fim, o módulo que sistematiza o projeto de interação ensinoserviço-comunidade, PINESC. O sistema de avaliação segue o proposto pelo método PBL.

\section{Aprendizado Baseado em Problemas: Breve Descrição}

O Aprendizado Baseado em Problemas destaca o uso de um contexto clínico-social para o apren-dizado, promove o desenvolvimento de habilidades de trabalhar em grupo e também estimula o estudo individual, de acordo com os interesses e o ritmo de cada estudante. $\mathrm{O}$ aprendizado passa a ser centrado no aluno, que sai do papel de receptor passivo para o de agente e principal responsável pelo seu aprendizado. Suprime-se a figura do professor, que ministra aulas magistrais, rege a cátedra. Ele é substituído pelo tutor, que tem a função de facilitador da aprendizagem. Os profissionais que atuam como tutores têm a oportunidade de conhecer bem os estudantes e de manter contato com eles durante todo o curso.

O curso de Psicologia conta com um corpo docente fixo, que trabalha em tempo integral para o curso e se divide nas funções de tutoria, coordenação de módulo, coordenação de avaliação, supervisão de estágios, orientação de laboratórios e habilidades, grupos de planejamento de módulos, consultoria e conferências.

Docentes de outros cursos participam também de conferências, consultorias, grupo de planejamento dos módulos e orientação de laboratórios e habilidades quando a temática se refere a outras áreas do conhecimento.

O professor-tutor deve conhecer os objetivos e toda a estrutura do módulo temático. Deve ter sempre em mente que o PBL é centrado no aluno, e não no professor; deve assumir a responsabilidade pedagógica no processo de aprendizagem; deve estimular no grupo a participação de todos; estimular uma cuidadosa e minuciosa análise do problema; estimular que os alunos façam a distinção entre questões principais e secundárias do problema; deve inspirar confiança nos alunos; não ensinar o aluno e, sim, ajudá-lo a aprender a aprender; usar os seus conhecimentos apropriadamente e na hora certa; formular questões inteligentes no grupo tutorial e não fornecer explicações; não intimidar os alunos com demonstração de seus conhecimentos; sumarizar a discussão somente quando necessário; avaliar o processo e o conteúdo (resultados alcançados); estar alerta para problemas individuais dos alunos e disponível para discuti-los quando interferirem no processo de aprendizagem e oferecer a experiência vivenciada nos grupos tutoriais para o aprimoramento do currículo.

A metodologia do PBL enfatiza o aprendizado autodirigido, centrado no estudante. Grupos de até doze estudantes se reúnem com um tutor duas ou três vezes por semana. Ele não ensina da maneira tradicional, mas facilita a discussão dos alunos, conduzindo-a quando necessário e indicando os recursos didáticos úteis para cada situação.

Uma sessão tutorial inicial trabalha os conhecimentos prévios dos estudantes sobre o assunto apresentado; os problemas são primeiramente identificados e listados, e, em seguida, são formulados os objetivos de aprendizado, com base em tópicos úteis para o esclarecimento e a resolução dos problemas. Na etapa seguinte, os estudantes vão trabalhar independentemente, na busca de informações e na sua elaboração antes da próxima sessão tutorial, quando as informações trazidas por todos serão discutidas e integradas no contexto do caso-problema.

Segundo Dolmans e Snellen-Belendong (1995,p.10)

"Por meio del análisis de las tareas en el grupo de aprendizaje, los estudiantes están activando sus conocimentos previos referentes a la tarea. Sobre la base de estos conocimientos previos, los estudiantes piensan em posibles explicaciones, lo que facilita el procesamientoy la retención de la información nueva".

Ou seja, no PBL os conhecimentos e experiências prévias não são ignoradas, mas pelo contrário, são 
aproveitadas para a construção do conhecimento acadêmico a partir das experiências dos alunos, o que parece contribuir para que a retenção das informações seja mais eficiente. Também o fato de os conteúdos serem discutidos e analisados em grupo serve como recurso facilitador da aprendizagem.

O currículo baseado em um método PBL objetiva apresentar seus conteúdos ao aluno de modo integrado e integrador de conhecimentos. O primeiro momento do currículoé a determinação de suas finalidades. Com base nessa definição, prepara-se um elenco de temas que o aluno deve saber e dominar. Esse elenco é analisado, situação por situação, para que se determine que conhecimentos o aluno deverá possuir para cada uma delas, constituindo objetivos de estudo, que são agrupados em módulos temáticos por afinidades. Cada tema, ou conjunto afim de temas, será contemplado em problema formulado para ser discutido em um grupo tutorial quando se tratar de um tema que diga respeito à esfera cognitiva. Temas relativos à esfera de habilidades serão abordados em laboratórios, ambulatórios, ou outros locais onde se possa desempenhar o treinamento das habilidades requeridas. Estágios em serviços de graus variados de complexidade são programados para várias fases do curso, buscando integrar práticas relativas às esferas cognitiva e de habilidades.

Em um currículo no qual se pretenda o preparo de um profissional generalista, geralmente parte-se das condições, características e patologias mais prevalentes na região onde o aluno vai atuar e nas práticas e habilidades que aquele profissional costuma desempenhar tradicionalmente na região. A esfera cognitiva do currículo PBL deve garantir que o aluno estude situações suficientes para se capacitar a procurar o conhecimento por si mesmo quando se deparar com uma situação problema, e internalizar essa atitude como parte de seu comportamento como profissional.

Ocurrículo PBL deve sofrer revisão permanente, a partir da retroalimentação feita à comissão de currículo, pelos tutores, monitores de estágios e pelas avaliações cognitivas e de habilidades. A comissão de currículo deve ter caráter permanente, sendo que seus membros sofrem rodízio regular com os demais membros da escola. Geralmente, a substituição não é total, mas parcial, de modo que, ao cabo de algum tempo, toda a comissão seja substituída. Esse método de substituição garante a permanência membros experientes convivendo com novos membros na comissão e a continuidade do trabalho de revisão permanente do currículo.

O grupo tutorial é a base do método do aprendizado baseado em problemas. No grupo, como já referido anteriormente, os alunos são apresentados a um problema pré-elaborado. Esse problema deve atender a determinações curriculares e, dentro de um módulo temático, abordar um tema do conhecimento. De sua discussão inicial, os alunos deverão formular objetivos de aprendizado. Um problema bem formulado leva o grupo de alunos a eleger objetivos de aprendizado análogos aos imaginados pelos especialistas das várias disciplinas como necessários para o crescimento cognitivo do aluno daquele tema específico.

O método de ensino PBL busca contemplar, desse modo, as premissas epistemológicas da aprendi-zagem, por meio de situações que podem configurar-se como ambientes facilitadores da aprendizagem significativa.

Um grupo tutorial é composto por um tutor e, no máximo, doze alunos. Dentre os alunos, um será o coordenador e outro o secretário da sessão tutorial. Os papéis de coordenador e de secretário alternam-se entre os alunos do grupo de sessão a sessão, de forma a propiciar que todos sejam coordenadores e secretários.

A discussão de um problema se desenrola em duas fases: na primeira, o problema é apresentado e os alunos formulam os objetivos de aprendizagem a partir da discussão do mesmo, valorizando-se a experiência prévia dos alunos; na segunda fase, após estudo individual realizado fora do grupo tutorial, os alunos rediscutem o problema à luz dos novos conhecimentos adquiridos, confrontando as diversas contribuições trazidas ao grupo com a sua aquisição individual. $\mathrm{Na}$ hipótese de não se elaborar a síntese pretendida, pode haver uma terceira fase para cumprir esse objetivo. Entretanto, essa situação é pouco freqüente.

O aluno coordenador deverá garantir a discussão do problema de forma metódica e fazer com que todos os membros do grupo participem da discussão. O método de condução sugerido é o dos sete passos:

leitura do problema, identificação;

identificação dos temas propostos pelo enunciado;

formulação de hipóteses explicativas para os problemas identificados no passo anterior (os alunos se utilizam dos conhecimentos de que dispõem sobre o assunto);

resumo das hipóteses;

- formulação dos objetivos de aprendizagem (trata-se da identificação do que o aluno deverá estudar para aprofundar os conhecimentos incompletos formulados nas hipóteses explicativas);

- estudo individual dos assuntos levantados nos objetivos de aprendizado;

\section{O currículo PBL deve sofrer revisão permanente, a partir da retroalimentação feita à comissão de currículo, pelos tutores, monitores de estágios e pelas avaliações cognitivas e de habilidades.}


Vera Lucia Kodjaoglanian, Clarice Cristina Andrade Benites, Irma Macário, Maria Celia Esgaib Kayatt Lacoski, Sonia Maria Oliveira de Andrade, Vera Nice Assumpção Nascimento, José Lúcio Machado

retorno ao grupo tutorial para a rediscussão do problema frente aos novos conhecimentos adquiridos na fase de estudo anterior.

O aluno-secretário deverá garantir a anotação conveniente das várias etapas da discussão do grupo de forma que este não se perca na discussão e não volte a pontos já discutidos anteriormente. Os outros alunos participantes do grupo devem se esforçar para realizar uma boa discussão do problema, respeitando as diretrizes do coordenador do grupo.

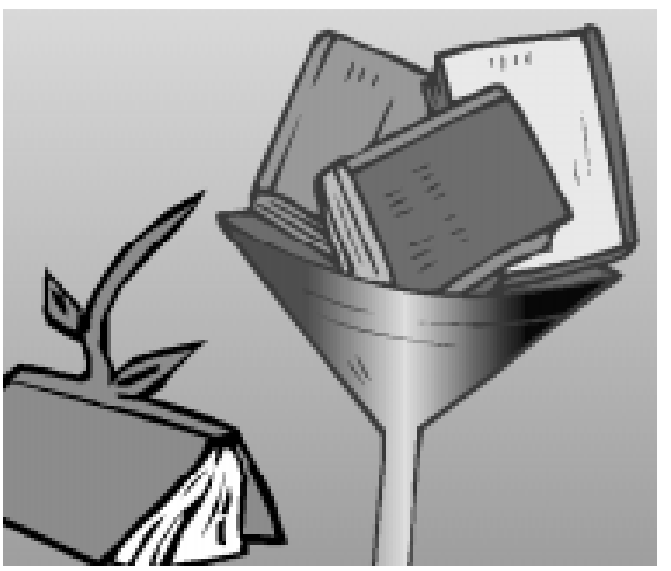

práticas, talvez uma das experiências mais importantes seja a integração dos serviços de saúde, comunidade e universidade, que propicia contato direto com a realidade,

possibilitando ao aluno a aprendizagem relacionada à realidade de seu futuro profissional, bem como o interesse pela ałuação generalista e de atenção social.
O docente-tutor deve garantir o funcionamento do grupo, a presença de coordenador e secretário, a participação de todos e a discussão não distante do tema, de forma que os alunos possam chegar a objetivos de aprendizado próximos daqueles previstos para aquele problema. O tutor tem uma visão geral do módulo temático e específico de cada problema. É instruído por material preparado e conhece de antemão os objetivos de aprendizado pretendidos para cada problema. Não deverá, entretanto, impor esses objetivos, nem desvendá-los para os alunos. Tampouco é esperado que ele dê uma aula para os alunos. Deve exigir do grupo que esteja atento ao texto do problema e que a discussão respeite esse texto. Deve ter um bom entendimento do tema em discussão, mas não é necessário que seja um especialista no assunto.

Como suporte à busca da aprendizagem necessária, os estudantes contam com os seguintes recursos:

-Laboratórios de informática interligados em rede e que disponibilizam bases de dados científicos contendo referências bibliográficas e textos científicos na íntegra;

Consultorias oferecidas por docentes vinculados à instituição e convidados;

- Sessão comentada de vídeos com a presença de docentes relacionados à área de conhecimento a ser analisada;

- Conferências (2 por semana), com o objetivo de apresentar temas relevantes à prática profissional, sempre com uma abordagem interdisciplinar e multiprofissional;

Laboratórios de habilidades, no qual o aluno tem a oportunidade de verificar na prática as questões relacionadas ao módulo que está sendo estudado, além de adquirir o conhecimento da aplicação apropriada de técnicas e procedimentos próprios da prática profissional.

Estudos autodirigidos, individuais ou coletivos, na biblioteca ou base de dados/Internet, adquirida especialmente para que os estudantes possam ampliar as suas pesquisas bibliográficas.

\section{A Aprendizagem Baseada na Prática, na Comunidade e nos Laboratórios de Habilidades}

A aquisição de habilidades em um currículo PBL deve ter início desde o primeiro ano de curso. Devem-se aproveitar as oportunidades de aprendizado oferecidas pelas várias modalidades de atenção à saúde desenvolvidas na sociedade, das mais simples às mais complexas.

Todas as oportunidades de aprendizado prático podem e devem ser utilizadas, organizadas segundo o esquema proposto no currículo e baseadas nas habilidades que se prevêem necessárias para a formação do tipo de profissional que a escola pretende formar. Há muitas vantagens em expor o aluno precocemente a ambulatórios e atividades de atenção à saúde da população e não há razões para não se aproveitar essa experiência, adaptando a prática às exigências do currículo. Para essas atividades, é necessário o monitoramento dos alunos por professores capacitados.

Dentro dessas práticas, talvez uma das experiências mais importantes seja a integração dos serviços de saúde, comunidade e universidade, que propicia contato direto com a realidade, possibilitando ao aluno a aprendizagem relacionada à realidade de seu futuro profissional, bem como o interesse pela atuação generalista e de atenção social.

A partir do 10 semestre do curso, o aluno é colocado em contato com a realidade pelo Programa de Integração Ensino-Serviços-Comunidade-PINESC e passa um dia da semana na Rede Municipal de Saúde, mais precisamente no Distrito Norte da cidade, onde ele é distribuído por todas as unidades básicas de saúde, no intuito de iniciar uma compreensão do funcionamento do sistema local de saúde, conhecer os papéis desenvolvidos por diversos profissionais em todos os níveis de escolaridade, compreender o funcionamento dos organismos colegiados existentes 
na região e identificar o papel dos usuários do sistema (Ito, 1995), bem como conhecer o trabalho desenvolvido pelas equipes de saúde da família.

No primeiro ano, o aluno reconhece o ambiente do ponto de vista das condições de vida e moradia daquela coletividade, para, a partir do segundo ano, progressivamente numa elevação de complexidade, poder debruçar-se um pouco mais sobre a compreensão dos processos psicológicos que ocorrem naquelas famílias seguido de possibilidades de intervenção sob supervisão profissional.

A partir do $2^{\circ}$ ano, o aluno é colocado no PINESC com psicólogos da rede pública, onde tem a oportunidade de vivenciar diversas atividades e funcionamentos dos serviços de saúde mental ao longo de seu curso de graduação.

A aprendizagem baseada na prática é prioridade no currículo de Psicologia, reservando-se dois períodos semanais para o desenvolvimento de atividades práticas nos anos iniciais da graduação.

A inserção do aluno na realidade é fator decisivo para que ele tenha uma visão bastante verdadeira do mundo que o circunda, para que ele possa atuar de forma adequada profissionalmente.

Porém não há receita pronta para o ensino de habilidades. As modalidades de ensino a serem desenvolvidas dependem da realidade e da capacidade de criar oportunidades para esse tipo de aprendizado. Tampouco o PBL remete a um ensino prático centrado em unidades de saúde. A recomendação de que haja exposição dos alunos a esse tipo de senviço e outras modalidades de atenção comunitária à saúde é preconizada internacionalmente, e não uma recomendação exclusiva do PBL. Seguir essa recomendação, e em que grau, é uma decisão da universidade.

No curso de Psicologia, atendendo às prerrogativas para a formação do profissional licenciado pelo curso, ao longo de quatro anos, iniciando no primeiro semestre, é desenvolvido o estágio de prática de ensino, ocasião em que o aluno entra em contato com a realidade mediante observação e posterior intervenção. Oestágio se dá em estabelecimentos integrantes do Projeto MAIS - da Prefeitura Municipal de Campo Grande, Mato Grosso do Sul. Durante o estágio, os acadêmicos observam a unidade escolar, com o objetivo de conhecer a realidade e a dinâmica institucional no processo ensino-aprendizagem; conhecem e estudam as diversas metodologias aplicadas e as existentes; realizam projetos acadêmicos sobre a realidade da escola/ comu-nidade.

Há também o laboratório de habilidades em teorias e técnicas psicoterápicas, dinâmica de grupo e técnicas de exame psicológico a partir do segundo ano, que se propõe a desenvolver habilidades técnicas inerentes à atuação do psicólogo. A partir do terceiro ano, tem início o Laboratório de Metodologia de Pesquisa, culminando com a produção do Trabalho de Conclusão de Curso (Monografia).

\section{Avaliação do Aluno e do Curso}

A avaliação em um currículo baseado em PBL tem duas finalidades: a avaliação da progressão do aluno e a avaliação da qualidade dos trabalhos pedagógicos; assim, ela não é exclusiva do método, ao contrário, identifica-se com os objetivos de qualquer processo avaliativo, voltado para o bom andamento do ensino e do currículo.

A avaliação modular ocorre ao fim de cada um dos módulos temáticos, de habilidades ou de integração ensino-serviço-comunidade. Refere-se ao conteúdo desses módulos e tem por finalidade principal avaliar a qualidade do módulo. Um módulo deve levar os alunos a atingirem determinados objetivos de conhecimento.

A avaliação progressiva ocorre em intervalos regulares. Tem por finalidade avaliar a progressão dos conhecimentos dos alunos. Um dos modelos de avaliação progressiva é a aplicação de uma prova comum a todos os alunos do curso, independentemente de sua série, com um número fixo de questões que versem sobre o conteúdo de todo o curso. Um bom parâmetro para determinar a profundidade dessas questões e o balanceamento das disciplinas na prova é o perfil determinado pelo currículo e as exigências legais vigentes no País para aquela graduação. Em um currículo PBL, é fundamental que o aluno receba retroalimentação quanto ao seu desempenho nessas avaliações, assim como ao desempenho relativo de seus parceiros. Sua colocação entre esses parceiros permitir-lhe-á avaliar se seu esforço está adequado ou inadequado e em áreas do conhecimento precisa melhorar seu desempenho.

A avaliação de habilidades é constituída de uma observação metódica do desempenho do aluno na realização das habilidades esperadas para o seu desenvolvimento profissional. A estratégia metodológica Objective Structure Clinical Examination (OSCE) consiste em gincana que compreende situações preparadas para o desempenho dessas habilidades. Há uma banca que dispõe de um fluxograma de desempenho preparado para cada situação específica.

A avaliação do módulo de integração ensino-senviçocomunidade se dá através dos relatórios confeccionados pelos alunos, cumprimento satisfatório das tarefas exigidas para aquele período 
Vera Lucia Kodjaoglanian, Clarice Cristina Andrade Benites, Irma Macário, Maria Celia Esgaib Kayatt Lacoski, Sonia Maria Oliveira de Andrade, Vera Nice Assumpção Nascimento, José Lúcio Machado

e avaliação da postura e desempenho do acadêmico pelo preceptor da Unidade e pelos supervisores.

A avaliação formativa acontece permanentemente entre os alunos e com o tutor, constando de avaliação interpares em que os alunos se avaliam uns aos outros; na auto-avaliação, os alunos e o tutor se auto-avaliam; avaliação do tutor pelo aluno, e avaliação do aluno pelo tutor. Essa avaliação objetiva verificar o interesse, a conduta, a responsabilidade e o relacionamento interpessoal, e é realizada oralmente e, em menor freqüência, por escrito.

A avaliação somativa, realizada por escrito, tem a peculiaridade de se basear nos objetivos do módulo e busca avaliar o conhecimento teórico adquirido.

Por fim, para que o modelo pedagógico seja aperfeiçoado, o sistema de monitoramento do curso é amplo, participativo e contínuo.

Os alunos e docentes avaliam o corpo docente, os problemas, as conferências e as sessões de vídeo durante o desenvolvimento das atividades do módulo e, ao final do módulo, fazem a avaliação deste como um todo, considerando a organização, o conteúdo, o sistema de avaliação, a biblioteca do campus e os laboratórios de habilidades.

\section{Conclusão}

A pedagogia da interação supera com vantagens a pedagogia da transmissão passiva de conhecimentos, utilizada nos métodos tradicionais de ensino, facilitando o desenvolvimento do método próprio de estudo, possibilitando que o aluno aprenda a selecionar criteriosamente os recursos educacionais mais adequados, a trabalhar em equipe e a aprender a aprender.

Com essa concepção de ensino, essa Universidade propõe a preparação de um profissional de Psicologia com formação geral, sólida e integral. O objetivo principal do PBL é a conquista de um profissional criativo, cooperativo, com iniciativa, capacitado para continuar a buscar conhecimentos após a graduação, comprometido com as transformações sociais.

Essa tarefa, realmente inovadora no âmbito da educação formal, supõe uma ruptura com as concepções tradicionais do ensino e, fundamentalmente, com as formas acadêmicas desvinculadas da prática real da profissão do psicólogo.

Nesse sentido, a reforma das práticas pedagógicas tem sido uma preocupação das instituições de ensino neste início de século. Essa necessidade surge com a mudança dos paradigmas educacionais baseados na urgência da adequação às culturas contemporâneas social, pois não há como desvincular mais a ciência do saber comum, já que aquela existe para este e a partir deste, uma vez que não há como desvincular a academia da realidade social, pois aquela existe desta e para esta deve voltar-se.

A nova proposta curricular para o curso de Psicologia da UNIDERP é inovadora em sua metodologia, funciona na prática desde o início de 2000, mas quer atender uma antiga necessidade: a Universidade a serviço da comunidade, formando profissionais mais cidadãos, conhecedores da realidade social, cultural e econômica brasileira e, acima de tudo, preparados para atuar em conformidade com essa realidade.

\section{Esse currículo tem como objetivo:}

Propiciar visão integral e permitir ajustes em decorrência das transformações ocorridas no mundo do trabalho; IAbordar visão humanística que considere os aspectos biopsicossociais, filosóficos, antropológicos, políticos, econômicos e culturais;

Despertar a consciência de valorização da categoria profissional do psicólogo;

Ser um projeto pedagógico coletivo, que integre e que permita uma prática educativa, com professor e aluno sendo sujeitos integrantes no processo ensinoaprendizagem;

Possibilitar integração entre o ensino e a prática profissional;

Possuir eixos de conhecimentos a serem desenvolvidos durante todo o curso por composição de blocos temáticos verticais, horizontais e intermediários.

Enfim, o modelo pedagógico do curso está fundamentado nos princípios da pedagogia interativa, de natureza democrática e pluralista, com um eixo metodológico firmemente estabelecido e que priorize metodologias ativas e com diversificação de cenários de ensino e aprendizagem. Esse modelo deve garantir a terminalidade do curso, proporcionando uma formação geral e integral do profissional psicólogo.

Com essa metodologia, pretende-se conjugar o enfoque pedagógico que melhor desenvolva os aspectos cognitivos da educação (aprender a aprender), com o enfoque que permita o melhor desenvolvimento das habilidades psicomotoras e de atitudes (aprender fazendo). 


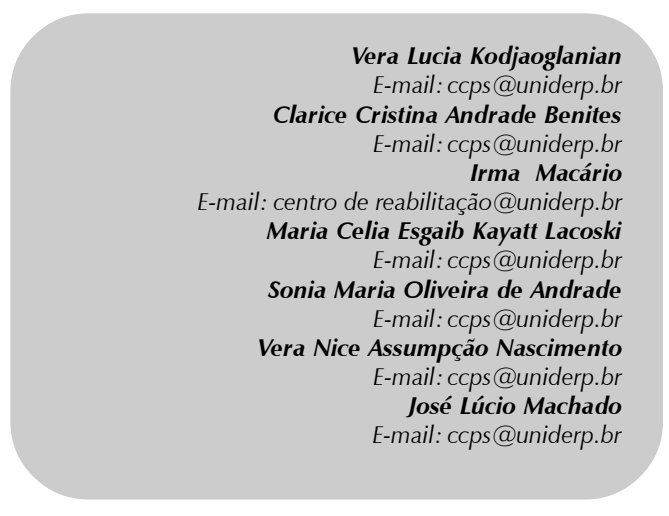

Recebido 06/06/00 Aprovado 22/11/02

Almeida, MJ. ( 1999).Educação Médica e Saúde: Possibilidades de Mudança. Londrina/Rio de Janeiro: Ed. UEL/ABEM.

Almeida, M.; Feuerweerker, L.; Llanos (1999). M. Educação dos Profissionais de Saúde na América Latina: Teoria e Prática de um Movimento de Mudança. São Paulo: Hucitec.

Bordenave, JD; Pereira, AM.(1977). Estratégias de Ensinoaprendizagem. Rio de Janeiro: Vozes.

Davini, Maria Cristina. Currículo Integrado. Guia curricular do projeto GERUS/Mimeo.

Dolmans, S.; Snellen-Balendong, H.(1995). Educacion Médica Basada en Problemas. Maastricht, Holanda: Universidade de Maastricht.

Freire. P. (2000).Pedagogia da Autonomia: Saberes Necessários à Prática Educativa. São Paulo: Paz e Terra.

Ito, Ana, et al. (1995). O Processo de Construção Coletiva de um Projeto Inovador: o Peepin (Gestando a Escola dos Nossos Sonhos). Londrina: Semina, set. v.16, pp.7-13, Número especial.

Kisil, M.; Chaves, M.M.. Programa UNI: uma Nova Iniciativa na Educação dos Profissionais de Saúde. Battle Creek: Fundação W.K.Kellogg, 1994.

Kodjaoglanian, V. L. (2000).Guia Pedagógico do Acadêmico do Curso de psicologia. Campo Grande: Editora UNIDERP.

Komatsu, R.S; et al. (1998). Aprendizagem Baseada em Problemas. In: Marcondes, E; Lima-Gonçalves, E. Educação Médica. São Paulo: Sarvier.
Komatsu, R.S; etal. (1998). Aprender a Aprender: Guia do Processo de Ensino-aprendizagem. 2 ${ }^{\underline{a}}$ ed. Marília: Faculdade de Medicina de Marília.

Mizukami, M. G. N. (1986). Ensino: as Abordagens do Processo. São Paulo: EPU.

Monroe, P. (1972).História da Educação. São Paulo: Companhia Editora Nacional.

Piagett, J. ( 1983). A Epistemologia Genética e Outros Textos. São Paulo: Abril Cultural.

Rodrigo. M. J.; Arnay, J: et ali. ( 1998).Conhecimento Cotidiano, Escolar e Científico:Representação e Mudança. São Paulo: Ática.

Rosa, S. (1998). Construtivismo e Mudança. São Paulo: Cortez.

Saviani. D. Escola e Democracia. São Paulo: Cortez, 1991.

Unicef. (1978). Relatório da Conferência Internacional realizada em Alma-Ata. URSS

Uniderp. (1999). Projeto Pedagógico do Curso de Psicologia da UNIDERP. Campo Grande: Mimeo.

Universidade de Colima.(1999).Curriculum Integrado y Aprendizage Centrado en el Estudante: Projeto Piloto do Curso de Psicologia. México: Colima.

University Maastricht. (1999-2000).Prospectus, Faculty of Psychology.

Venturelli, J.(2000). Educacion médica: Nuevos Enfoques, Metas y Métodos. Washington; Organización Panamericana de Salud, 1997. (Programa Ampliado de Libros de Texto y Materiales de Instrucion Paltex - Serie Salud y Sociedad, n.5).

\section{Referências} bibliográficas 